\title{
RESEARCH
}

\section{Self-Assessment of Therapeutic Decision Making in Pharmacy Students}

\author{
Carmen Abeyaratne, BSci, To Nhu Pham, Daniel Malone, PhD \\ Monash University, Faculty of Pharmacy and Pharmaceutical Sciences, Parkville, Australia
}

Corresponding Author: Daniel Malone, Monash University, Faculty of Pharmacy and Pharmaceutical Sciences, 381 Royal Parade, Parkville VIC, Australia 3052. Tel: +61399039576. Email: dan.malone@ monash.edu.

Submitted April 19, 2021; accepted August 13, 2021; ePublished September 2021

Objective. The ability of pharmacy students to self-regulate and reflect on knowledge and skills is important as proficient self-assessment skills guide learning strategies and prompt students to bridge their knowledge gaps. The objective was to determine how well third-year pharmacy students self-assess, to explore the rationales behind their self-assessments and determine whether there is a correlation between self-assessment accuracy and academic performance.

Methods. A quasi-experimental one-group pre-/post-test design was conducted with third-year pharmacy students. Examiner grades, student self-assessment grades, comparative reports and end-of-semester grades were collected. Students were categorised into tertiles based on academic performance for data analysis. Paired t-tests, Pearson's $r$ and percentage agreements were conducted to investigate self-assessment accuracy. Correlational statistical tests were implemented to examine the relationships between self-assessment accuracy and academic performance.

Results. 162 third-year pharmacy students were included. On average, students demonstrated poor self-evaluation skills and underestimated themselves by $4.9 \%$. Lower performing students were generally overconfident in evaluating their performance. There was no significant correlation between self-assessment accuracy and academic performance on the subsequent end-of-semester examination question.

Conclusion. On average students tended to underestimate their academic performance. Further research on selfassessment can help understand how students think about their performance which may help to improve education methods such as inclusion of reflective practices after case-based activities.

Keywords: pharmacy students, self-assessment, metacognition

\section{INTRODUCTION}

Metacognition refers to "one's knowledge concerning one's own cognitive process" , and is an integral skill for health care professionals.. For pharmacy students, the ability to self-regulate and reflect on their own knowledge and skills is essential because proficient metacognition guides learning strategies and prompts students to bridge their knowledge gaps. ${ }^{2,3}$ Good awareness of metacognitive skills in the classroom has correlated with higher achievement, possibly due to higher levels of problem-solving skills and critical self-reflection that facilitates the academic journey. ${ }^{4}$

One way to evaluate metacognitive skills in pharmacy students is to determine how accurately they self-assess their performance. ${ }^{5}$ Self-assessment accuracy is frequently demonstrated by an acceptable variation between self and an expert's ratings of academic performance based on a standardised grading scheme. A meta-analysis showed that students lack self-assessment abilities and, as a result, misjudge their performance, with lower-performing students overestimating their capabilities. ${ }^{6}$ Inflated self-assessment is a well-documented phenomenon in undergraduate pharmacy students. ${ }^{7-9}$ However, a more recent study reported that most pharmacy students underpredicted their grades and high-performing students demonstrated more accuracy in error identification. ${ }^{10}$ This shows that students of varying performance possess different patterns of self-assessment accuracy.

Methodological designs involving self-assessments after completing a course work related activity have shown that student self-assessment accuracy may change over time. Some researchers have reported overconfidence of students and no improvement of self-assessment accuracy ${ }^{11-13}$ but results from another study showed improvement in self-awareness over three semesters. ${ }^{14}$ After the introduction of "benchmark performance" (defined in this context as a self-assessment of performance compared with an expert response), self-ratings became more aligned with expert's ratings. ${ }^{13}$ Due to the different approaches employed in the literature, self-assessment accuracy warrants further investigation.

Given that the utilisation of "benchmark performance" was shown to improve the accuracy of self-assessment, a primary aim of this study was to determine how well students evaluate their action plan after viewing expert practitioner responses when using the integrating Science and Practice (iSAP) format. ${ }^{15}$ The iSAP format is designed as an active learning method that incorporates metacognitive strategies to support self-regulated learning. The iSAP format involves a case/scenario presented in realistic fashion, a student written action plan, an expert response, and a student comparative report or reflective analysis ${ }^{15}$ (Figure 1). 
The iSAP format was introduced into the new Monash University pharmacy degree in Australia to promote a patient-centred action plan and reflective practice. One key feature of the degree is a student-directed learning approach and a focus on student self-development of essential skills for a practising pharmacist such as therapeutic problem solving and communication. Through the iSAP process, students are able to develop skills via the use of expert and peer feedback, real-life case-based studies and student reflection.

In addition to investigating self-assessment accuracy of third-year pharmacy students in the Monash pharmacy degree, another aim was to determine whether there was a correlation between self-assessment accuracy and academic performance. Additionally we sought to determine if there was a relationship between self-assessment accuracy and subsequent performance on an examination question that assessed similar content. Another aim of this study was to understand the rationales that students provided for their performance and gain insight into how they self-assess their performance by analysing self-reflections. Based on previous studies on self-assessment it was hypothesised that students would display low to moderate ability to self-assess with low-performing students being more likely to overestimate their performance.

\section{Research questions (RQs)}

- RQ1: How well do pharmacy students self-assess their action plan performance after viewing an expert response?

- RQ2: How does self-assessment accuracy relate to academic performance on an iSAP assessment completed by pharmacy students?

- RQ3: How does self-assessment accuracy relate to the performance of pharmacy students on a similar end-ofsemester examination question?

- RQ4: How does self-assessment accuracy relate to changes in pharmacy students' performance between the iSAP assessment and a similar end-of-semester examination question?

- RQ5: What types of reasons do pharmacy students provide for their performance on the iSAP assessment compared with expert responses?

\section{METHODS}

A quasi-experimental one-group pre-/post-test research design was used to measure the impact of the intervention of viewing an expert response, self-assessment and reflections, by comparing scores before and after its implementation, i.e., iSAP assessment grades and end-of-semester examination grades.

The subjects were third-year pharmacy students who were enrolled in a therapeutics course. Excluded from the study were students who were absent from the assessment, provided an incomplete or no self-assessment, opted out of a research data registry, or were involved in the data analysis process.

Students were given 100 minutes to review an oncological case presented in the iSAP format and create their action plan using a standard model of patient care to identify medication-related problems (MRPs) and provide therapeutic reasoning for their recommendations. After they submitted the management plan to be assessed by a course examiner the students viewed an expert response. Two days later students were asked to self-assess their management plan using a similar grading rubric as the examiner and complete a comparative report (using the "What?, So what?, Now what?" format $\left.{ }^{16}\right)$. One month later, students completed the end-of-semester exam for this course. There was a single examiner who graded both the iSAP management plan and the end-of-semester examination question that evaluated the same content on the iSAP case for consistency (Figure 1).

As part of the standard quality improvement processes for the pharmacy degree and consistent with the Student Privacy Collection Statement, student performance data was collected, de-identified, summarised, and shared with the cohort (Monash University Human Ethics Project ID11577).

The key data points collected were management plan rubric grades completed by the course examiner and students (their self-assessment), grades for an end-of-semester examination question that evaluated similar content to that of the iSAP case and student comparative reports. The data points were then used to calculate the iSAP course examiner and self-assessment grades, and the self-awareness score and type of each student.

The grading rubric included eight criteria (Table 1). To calculate the iSAP course examiner grade and selfassessment grade, "Academic Integrity", "Rationale for Recommendation" and "Overall Evaluation" were excluded. This was to enable a more meaningful comparison between the iSAP grade and the end-of-semester examination question grade, since students were not assessed on their rationale for recommendation, use of references or their overall competency in the end-of-semester examination question. The final calculation for the iSAP course examiner grade and self-assessment grade was the sum of the grades awarded for the remaining criteria on a scale of $100 \%$.

To determine the self-awareness score the difference between iSAP examiner grade and self-assessment grade for each rubric criterion was calculated. All criteria except for Academic Integrity were considered in the selfawareness score. Absolute values (to avoid any negative and positive values cancelling each other out) of these differences were summed with 100 being the highest possible value. With values calculated in this manner there is an 
inverse correlation i.e., a value closer to 0 signifies higher self-assessment accuracy. To produce a direct correlation the value was taken away from 100, meaning that a value closer to 0 signifies lower self-assessment accuracy.

To determine the level of self-awareness for each student a deviation of 1-point on the scale has been deemed acceptable. ${ }^{17,18}$ Since the majority of the rubric criteria had a 4-point scale a deviation of 1-point in the scale is a difference of, on average, $25 \%$. Thus, an awareness score of $75 \%$ or greater was defined as high awareness and less than $75 \%$ as low awareness.

Data analysis undertaken for RQ1 and RQ4 was in groups according to student academic performance. Given the Dunning-Kruger effect ${ }^{19}$ if analysed as a whole there is a probability that the overestimation in lower-performing students could negate the underestimation in higher-performing students resulting in a misleading high level of accuracy. Students were categorized into tertiles, meaning there was an even distribution of students per group.

For RQ2, RQ3, and RQ4 the association between self-awareness and academic performance was investigated using Pearson's $r$ and regression analysis. In RQ4 a one-way ANOVA was conducted to better visualise the data and obtain more information about the difference between each group of students. Following this, a linear regression test was performed to investigate the relationship between self-assessment accuracy and changes in performance of students in the iSAP assessment compared to a similar end-of-semester examination question.

RQ5 involved analysing reflective reports of students by thematic analysis. Due to the large quantities of reflections and the repetitive themes found in the pilot study, we reported the qualitative results of the 21 participants. This number was chosen based on a preliminary scan of reflective reports that estimated saturation of responses to be evident after approximately twenty reports. Thus, a random sample of seven reports from each tertile was selected, totalling 21 reports. An iterative and inductive coding process was adopted to derive themes of reasoning rationales and reasoning patterns. Firstly, one coder read all the included reflections to create preliminary codes and develop a codebook, which was then reviewed by two other coders. Each reflection was coded with codes that described reasons given by students for their errors and the observed pattern of their self-assessment. Then, raw code patterns and themes across different comparative reports were combined and refined, and themes were identified and defined.

\section{RESULTS}

162 out of 215 students (75\%) enrolled in the PHR3041 course in 2019 were included in this study. Three students opted out of the study, one student was absent, 40 students did not provide a self-assessment, four students incompletely filled out the self-assessment rubric and five student researchers were excluded. A summary of the statistical analysis of research questions 1,2, 3 and 4 are included in table 2.

For RQ1: Self-assessment accuracy, students were categorised into tertiles based on their performance in the iSAP assessment. The highest tertile $(\mathrm{N}=55)$ had a self-assessed iSAP grade that was on average $19 \%$ below the grade given by the course examiner, suggesting a considerable underestimation of their ability. The mean difference appeared to be the lowest in the middle tertile $(\mathrm{N}=53)$, who underestimated their performance by an average of $7.7 \%$ compared with the grade given by the course examiner. The lowest tertile $(\mathrm{N}=54)$ rated their performance an average of $12 \%$ higher than the course examiner grade, suggesting an overestimation of their ability. Figure 2 shows that the self-assessment grades were widely distributed on the scale of 100, irrespective of the academic performance which indicates that students in each tertile had varying degrees of self-awareness.

A Pearson correlation showed that the correlation between self-assessment and course examiner grade of all students was poor $(\mathrm{r}=.27, p<.001)$. The lowest and middle tertiles demonstrated the same correlation coefficient $(\mathrm{r}=$ $.18, p=.10)$. However, the highest tertile demonstrated a negative but insignificant correlation coefficient $(\mathrm{r}=-.08, p$ $=.28)$.

The mean of course examiner and student self-assessment grades for each criterion in the iSAP assessment was calculated. There was a significant difference of $23 \%(p<.001), 9.3 \%(p=.002)$ and $11.3 \%(p<.001)$ between the means for "Overall Evaluation of Clinical Decisions", "Priority Identification" and "MRP Identification" respectively, which indicated that students underestimated themselves in these criteria.

RQ2 explored the relationship between self-assessment accuracy and academic performance on the iSAP case. A linear regression test showed a significant weak positive correlation between awareness and academic performance $(\mathrm{r}=.22, p=.005)$. As the iSAP grade increased by $1.0 \%$, awareness score increased by $.15 \%$. However, the R-squared value of .048 suggested a poor fit of the regression model, as only $4.8 \%$ of the variance in awareness was accounted for by the iSAP grade.

A linear regression test showed no relationship between awareness scores and academic performance on the subsequent end-of-semester examination question for RQ3 $(\mathrm{r}=.13, p=.11)$. RQ4 explored the relationship between self-assessment accuracy and changes in students' performance between the iSAP assessment and a similar end-ofsemester examination question. The regression test showed no relationship $(\mathrm{r}=-.04, p$-value $=.58)$. A one-way ANOVA was conducted to determine if there were any changes between the iSAP assessment grades and end-ofsemester examination grades of students with low and high awareness. On average, the grades for the end-of-semester examination question were lower than that of the iSAP assessment by an average of $15 \%$. In the lowest tertile, students with low awareness had a mean of +1.1 , suggesting an improvement of $1.1 \%$ in grades; whereas those with 
high awareness had a decrease of $3.7 \%$ in grades. On the other hand, for the middle tertile, both the high awareness and low awareness groups had a decrease in grades of $25 \%$ and $16 \%$ respectively. Similarly, for the highest tertile, the grades of students with high and low awareness were lower by $23 \%$ and $25 \%$ respectively. However, an ANOVA showed no significant differences, indicating that the two self-awareness groups from all tertiles had similar changes in performance between the iSAP assessment and the end-of-semester examination.

For RQ5: Students' self-identified reasons for their performance on the iSAP, 21 self-reflections were included. Students provided reflections on almost all criteria of the grading rubric - Medication Problem List, Patient Management Plan, but not Patient Education. Seven students stated that their MRPs were correct, but almost all of them $(n=20)$ were aware of their clinical errors regarding the MRPs, dose and duration of therapy, and monitoring points. Upon analysing student reflections, some patterns of self-assessment were identified. A proportion of students only reflected on their errors and did not comment on their success. In contrast, one student who grossly overestimated their abilities was unable to contrast their clinical plan with the expert response and only provided positive selfratings. Various answers were given in the "So what" section, which prompted students to consider the potential patient outcomes of their recommendations. Most students only commented on the negative consequences, but one student, who had a self-awareness score of $91 \%$, stated "we can expect good patient outcomes". Interestingly, some students chose to justify their incorrect treatment options instead of commenting on the possible outcomes of their recommendations.

The themes relating to the iSAP performance are shown in Table 3. Five major themes and their corresponding sub-themes were identified. Most themes related to their weaknesses but the aforementioned student with a self-awareness score of $91 \%$ stated that it was a confidence boost. Furthermore, most reasons for iSAP performance were attributed to their own shortcomings. However two external reasons emerged being "time constraint" and "resources are not clear.

\section{DISCUSSION}

Using the innovative approach of the iSAP format, the self-assessment accuracy of students and the rationales behind their evaluations was explored, and the association between self-awareness and future examinations was investigated.

In agreement with previous studies ${ }^{9,12,20,21}$, self-assessment abilities of students in this study were indicative of the Dunning-Kruger effect ${ }^{19}$ whereby lower-performing students tended to overestimate themselves and higherperforming students tended to underestimate themselves. Additionally, our results demonstrated that overall there was a low correlation between the self-assessed and examiner grade. ${ }^{12,}{ }^{21}$ Self-assessment of clinical knowledge and skills is a progressive process that requires practice to develop. ${ }^{9}$

Despite the similarities mentioned, our findings did not entirely align with previous literature. For example studies conducted on third-year pharmacy students found that they were generally overconfident in self-evaluating their grades. ${ }^{8,11}$ Substantial research conducted on other populations including pharmacy students from different year levels or medical students, also documented inflated self-assessment. ${ }^{9,22,23}$ However the participants in the current study as a whole underestimated themselves. Furthermore past studies indicated that more academically inclined students exhibit better self-awareness ${ }^{9,11}$ while our findings showed a very weak and non-significant correlation between self-assessment accuracy and academic performance.

Based on previous research conducted on meta-awareness ${ }^{24}$ it was hypothesised that proficient self-assessment abilities may improve subsequent academic performance. However, our findings showed no significant differences in terms of grades pre- and post-test amongst all tertiles, irrespective of self-assessment accuracy. This is potentially because being critical of oneself is a skill that requires development over time. Given the limited follow-up opportunities in our study and a time of only three weeks between the self-assessment and the end of semester examination, a significant improvement in metacognitive ability is unlikely. Additionally the average grade on the end-of-semester examination question was lower than the average iSAP grade, perhaps reflecting the more difficult nature of an end of semester examination worth a larger proportion of the course grade.

The strengths of this study include that it explored the relationship between self-assessment accuracy and future academic performance, of which there is currently minimal published data in the literature. Furthermore it may be the first study to test if the iSAP format has an impact on student self-assessment abilities and future performance. Contrary to the commonly evident phenomenon of self-assessment skill overestimation in pharmacy students, this study showed that on average, students tended to underestimate their academic performance according to only one comparison. Future studies can implement strategies such as reflective practice after workshops and ensure feedback from peers or preceptors is consistently sought to boost self-confidence and to enable follow through of student selfassessment skills over a period of time in order to produce a more reliable result.

Limitations include the lack of a control group. This was a consequence of the self-assessment and comparative report being compulsory as part of the course syllabus, and because this was the first time this course was first offered in 2019. Another limitation was that study participants only accounted for approximately $75 \%$ of thirdyear students at one pharmacy school and only one follow-up assessment was investigated to compare academic 
performance. Therefore, not only further larger scale studies, but also inclusion of more follow-up assessments and other pharmacy cohorts are needed to confirm the findings, to improve generalisability and improve reliability. Another limitation is that the relevance and reasoning of including the iSAP format was not outlined to students, therefore, there may not have been a vested interest of the students when completing the intervention, thus its full potential may not have been revealed. The end-of-semester examination question was situated at the end of the paper, which may have influenced the ability for students to answer the question due to potential time constraints.

Future studies should investigate the relationship between self-assessment abilities and subsequent academic performance. Self-awareness and metacognition require continual practice with feedback in order to develop. ${ }^{11}$ Tracking of students throughout a degree may determine how students develop self-awareness and improve their clinical decision making over time, or even after they complete their studies and are practising pharmacists.

\section{CONCLUSION}

On average students tended to underestimate their academic performance. Countermeasures to reduce selfassessment inaccuracies are essential to promote self-confidence. With further research on self-assessment, an understanding of student perceptions about their performance may improve education methods such as inclusion of reflective practices after case-based activities, to enable students to practice self-reflection and develop skills throughout their pharmacy career.

\section{ACKNOWLEDGEMENTS}

The authors wish to acknowledge Professor Marilyn Baird and Dr Allie Ford for their assistance in the creation of iSAP assessments, and the contributions of the following who assisted with this project as part of their pharmacy course requirements: Aisha Imam, Gia Pham, To Nhu Pham, Wan Zainina and Xin Hui Tan.

\section{REFERENCES}

1. Tanner KD. Promoting student metacognition. CBE Life Sci Educ. Summer 2012;11(2):113-120.

2. Siegesmund A. Using self-assessment to develop metacognition and self-regulated learners. FEMS Microbiol Lett. 2017;364(11).

3. Medina MS, Castleberry AN, Persky AM. Strategies for Improving Learner Metacognition in Health Professional Education. Am J Pharm Educ. May 2017;81(4):78.

4. Yusuff KB. Does self-reflection and peer-assessment improve Saudi pharmacy students' academic performance and metacognitive skills? Saudi Pharmaceutical Journal. 2015/07/01/ 2015;23(3):266-75.

5. Hansford BC, Hattie JA. The Relationship Between Self and Achievement/Performance Measures. Review of Educational Research. 1982;52(1):123-42.

6. Falchikov N, Boud D. Student Self-Assessment in Higher Education: A Meta-Analysis. Review of Educational Research. 1989;59(4):395-430.

7. Sharif S, Gifford LA, Morris GA, Barber J. An investigation of the self-evaluation skills of first year pharmacy students. Pharmacy Education: An International Journal of Pharmaceutical Education. 2007;7(4):295-302.

8. Naughton CA, Friesner DL. Comparison of pharmacy students' perceived and actual knowledge using the Pharmacy Curricular Outcomes Assessment. American journal of pharmaceutical education. May 10 2012;76(4):63.

9. Austin Z, Gregory PAM. Evaluating the accuracy of pharmacy students' self-assessment skills. Am J Pharm Educ. 2007;71(5):89-.

10. Schneider EF, Castleberry AN, Vuk J, Stowe CD. Pharmacy students' ability to think about thinking. Am J Pharm Educ. 2014;78(8):148-.

11. Steuber TD, Janzen KM, Walton AM, Nisly SA. Assessment of Learner Metacognition in a Professional Pharmacy Elective Course. American journal of pharmaceutical education. Dec 2017;81(10):6034.

12. Mort JR, Hansen DJ. First-year Pharmacy Students\&\#039; Self-Assessment of Communication Skills and the Impact of Video Review. Am J Pharm Educ. 2010;74(5):78.

13. Hawkins SC, Osborne A, Schofield SJ, Pournaras DJ, Chester JF. Improving the accuracy of self-assessment of practical clinical skills using video feedback--the importance of including benchmarks. Medical teacher. 2012;34(4):279-84.

14. Nisly SA, Sebaaly J, Fillius AG, Haltom WR, Dinkins MM. Changes in Metacognition Through SelfEvaluation During Advanced Pharmacy Practice Experiences. Am J Pharm Educ. 2019:ajpe7489.

15. Williams I, Schliephake K, Heinrich L, Baird M. Integrating Science and Practice (iSAP): An Interactive Case-Based Clinical Decision-Making Radiography Training Program. MedEdPublish. 2017:1-10.

16. Rolfe G. Reach touch and teach: Terry Borton. Nurse Education Today. 2014/04/01/ 2014;34(4):488-9.

17. Cochran SB, Spears MC. Student self-assessment and instructors' ratings: a comparison. Journal of the American Dietetic Association (USA). 1980. 
18. Coutts L, Rogers J. Predictors of student self-assessment accuracy during a clinical performance exam: comparisons between over-estimators and under-estimators of SP-evaluated performance. Acad Med. Oct 1999;74(10 Suppl):S128-30.

19. Kruger J, Dunning D. Unskilled and unaware of it: How difficulties in recognizing one's own incompetence lead to inflated self-assessments. J Pers Soc Psychol. 1999;77(6):1121-34.

20. Edwards RK, Kellner KR, Sistrom CL, Magyari EJ. Medical student self-assessment of performance on an obstetrics and gynecology clerkship. Am J Obstet Gynecol. Apr 2003;188(4):1078-82.

21. Parker RW, Alford C, Passmore C. Can family medicine residents predict their performance on the in-training examination? Fam Med. Nov-Dec 2004;36(10):705-9.

22. Abadel FT, Hattab AS. How does the medical graduates' self-assessment of their clinical competency differ from experts' assessment? BMC medical education. Feb 13 2013;13:24.

23. Watts WE, Rush K, Wright M. Evaluating first-year nursing students' ability to self-assess psychomotor skills using videotape. Nurs Educ Perspect. Jul-Aug 2009;30(4):214-9.

24. Colthorpe K, Ogiji J, Ainscough L, Zimbardi K, Anderson S. Effect of Metacognitive Prompts on Undergraduate Pharmacy Students' Self-regulated Learning Behavior. American journal of pharmaceutical education. May 2019;83(4):6646.

25. Baxter P, Norman G. Self-assessment or self deception? A lack of association between nursing students' selfassessment and performance. $J$ Adv Nurs. 2011;67(11):2406-13. 
Table 1. Grading Rubric for The iSAP Assessment and Student Self-Assessment

\begin{tabular}{|c|c|c|c|c|c|c|}
\hline CRITERIA & & PERFORMANCE INDICATORS & $\begin{array}{l}\text { Not meeting } \\
\text { expectations }\end{array}$ & $\begin{array}{l}\text { Approaching } \\
\text { expectations, but } \\
\text { needing more } \\
\text { consistency }\end{array}$ & $\begin{array}{l}\text { Substantially } \\
\text { approaching } \\
\text { expectations }\end{array}$ & $\begin{array}{l}\text { Meeting } \\
\text { expectations }\end{array}$ \\
\hline \multirow[t]{3}{*}{$\begin{array}{l}\text { MEDICAL } \\
\text { PROBLEM } \\
\text { LIST }\end{array}$} & $\begin{array}{l}\text { Priority } \\
\text { identification }\end{array}$ & $\begin{array}{l}\text { - Correctly prioritize Medical Related } \\
\text { Problems (MRP) according } \\
\text { to urgency/patient need }\end{array}$ & $\begin{array}{l}\text { INCORRECT } \\
\text { response }\end{array}$ & & & $\begin{array}{l}\text { CORRECT } \\
\text { response }\end{array}$ \\
\hline & $\begin{array}{l}\text { MRP } \\
\text { identification }\end{array}$ & $\begin{array}{l}\text { - Correctly identify the core issue or } \\
\text { cause of problem } \\
\text { - Clearly explain the potential or actual } \\
\text { impact on patient }\end{array}$ & $\begin{array}{l}\text { INCORRECT } \\
\text { or } \\
\text { NO essential } \\
\text { information }\end{array}$ & & $\begin{array}{l}\text { CORRECT } \\
\text { identification of } \\
\text { core issues, but } \\
\text { NO explanation } \\
\text { of the impact. }\end{array}$ & $\begin{array}{l}\text { BOTH } \\
\text { performance } \\
\text { indicators } \\
\text { demonstrated } \\
\text { CONSISTENTL } \\
\text { Y }\end{array}$ \\
\hline & $\begin{array}{l}\text { Rationale for } \\
\text { recommendation }\end{array}$ & $\begin{array}{l}\text { - Justify the rationale based on patient } \\
\text { specific factors and preferences } \\
\text { - Justify the rationale based } \\
\text { on medication related factors } \\
\text { - Justify the rationale based on best } \\
\text { evidence/practice from credible and rel } \\
\text { evant sources }\end{array}$ & $\begin{array}{l}\text { NONE } \\
\text { of the } \\
\text { performance } \\
\text { indicators } \\
\text { demonstrated } \\
\text { CONSISTENTL } \\
\text { Y }\end{array}$ & $\begin{array}{l}\text { SOME performance } \\
\text { indicators } \\
\text { demonstrated } \\
\text { CONSISTENTLY }\end{array}$ & $\begin{array}{l}\text { MOST } \\
\text { performance } \\
\text { indicators } \\
\text { demonstrated } \\
\text { CONSISTENTL } \\
\text { Y }\end{array}$ & $\begin{array}{l}\text { ALL } \\
\text { performance } \\
\text { indicators } \\
\text { demonstrated } \\
\text { CONSISTENTL } \\
\text { Y }\end{array}$ \\
\hline \multirow[t]{2}{*}{$\begin{array}{l}\text { PATIENT } \\
\text { MANAGEME } \\
\text { NT PLAN }\end{array}$} & $\begin{array}{l}\text { Recommendatio } \\
\mathrm{n} / \mathrm{s}\end{array}$ & $\begin{array}{l}\text { - Recommend patient- } \\
\text { centered treatment option that } \\
\text { is likely to produce an optimal patient } \\
\text { outcome } \\
\text { - Provides specific } \\
\text { instructions, using easily understood } \\
\text { language, including all applicable } \\
\text { details: name, dose, route, frequency } \\
\text { and duration }\end{array}$ & $\begin{array}{l}\text { UNSAFE or } \\
\text { INADEQUATE } \\
\text { treatment } \\
\text { option }\end{array}$ & $\begin{array}{l}\text { ADEQUATE/OPTIM } \\
\text { AL treatment option } \\
\text { BUT instructions are } \\
\text { not specific or easily } \\
\text { understood }\end{array}$ & $\begin{array}{l}\text { ADEQUATE } \\
\text { treatment option } \\
\text { AND } \\
\text { instructions are } \\
\text { specific and } \\
\text { easily } \\
\text { understood }\end{array}$ & $\begin{array}{l}\text { OPTIMAL } \\
\text { treatment option } \\
\text { AND } \\
\text { instructions are } \\
\text { specific, easily } \\
\text { understood }\end{array}$ \\
\hline & $\begin{array}{l}\text { Monitoring and } \\
\text { follow up plan }\end{array}$ & $\begin{array}{l}\text { - Articulate goals of therapy } \\
\text { - Develop a complete monitoring plan that } \\
\text { addresses efficacy with regard to goals } \\
\text { of therapy } \\
\text { - The monitoring plan also } \\
\text { addresses safety of therapy with regard } \\
\text { to potential toxicity }\end{array}$ & $\begin{array}{l}\text { NONE } \\
\text { of the } \\
\text { performance } \\
\text { indicators } \\
\text { demonstrated } \\
\text { CONSISTENTL } \\
\text { Y }\end{array}$ & $\begin{array}{l}\text { SOME } \\
\text { performance } \\
\text { indicators } \\
\text { demonstrated } \\
\text { CONSISTENTLY }\end{array}$ & $\begin{array}{l}\text { MOST } \\
\text { performance } \\
\text { indicators } \\
\text { demonstrated } \\
\text { CONSISTENTL } \\
\text { Y }\end{array}$ & $\begin{array}{l}\text { ALL } \\
\text { performance } \\
\text { indicators } \\
\text { demonstrated } \\
\text { CONSISTENTL } \\
\text { Y }\end{array}$ \\
\hline
\end{tabular}


Establish plan for follow-

up including who will perform

this, what will be monitored

and when this will be monitored

$\begin{array}{ll}\begin{array}{l}\text { PATIENT } \\ \text { EDUCATION }\end{array} & \begin{array}{l}\text { Patient } \\ \text { education / } \\ \text { counselling }\end{array} \\ & \\ \text { ACADEMIC } & \begin{array}{l}\text { Student critically } \\ \text { uses credible } \\ \text { sources to } \\ \text { develop and } \\ \text { support the } \\ \text { synthesis, } \\ \text { using correct } \\ \text { attribution }\end{array} \\ \text { OVERALL EVALUATION OF } \\ \text { CLINICAL DECISION }\end{array}$

- Provide clear, concise and specific instructions that patient can follow and understand

- Describe THREE important

points that you would explain about this

medication/condition (Note: Number of

points is subject to vary across cases

- Ensure all medical claims and statements are referenced, where indicated

- Include correct in-text

citations to all references

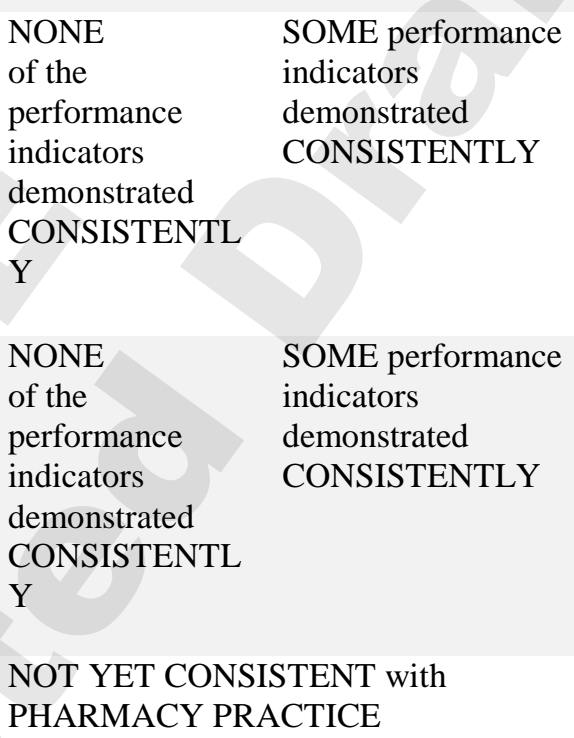

- Correctly identify the medication related problem

- Provide recommendation that is likely to produce an adequate or optimal patient outcome

- Provide specific

instructions, using easily understood

language
NOT ALL performance indicators demonstrated

\section{MOST}

performance

indicators

ALL

performance

$\mathrm{Y}$

\section{MOST}

performance

indicators

ALL

demonstrated

demonstrated

$\mathrm{Y}$
CONSISTENTL
CONSISTENT with PHARMACY PRACTICE

ALL performance indicators demonstrated 
Table 2. Summary of Statistical Analysis of Research Questions

\begin{tabular}{|c|c|c|c|c|c|}
\hline \multicolumn{2}{|c|}{ Research questions } & \multirow{2}{*}{$\begin{array}{l}\text { All } \\
+4.85 \% \\
(\mathrm{p}=.008)\end{array}$} & \multirow{2}{*}{$\begin{array}{l}\begin{array}{l}\text { Lowest } \\
\text { tertile }\end{array} \\
-12.29 \% \\
(\mathrm{p}<.001)\end{array}$} & \multirow{2}{*}{$\begin{array}{l}\begin{array}{l}\text { Middle } \\
\text { tertile }\end{array} \\
+7.71 \% \\
(\mathrm{p}<.001)\end{array}$} & \multirow{2}{*}{$\begin{array}{l}\begin{array}{l}\text { Highest } \\
\text { tertile }\end{array} \\
+18.91 \% \\
(\mathrm{p}<.001)\end{array}$} \\
\hline RQ1 & $\begin{array}{l}\text { Mean difference between examiner grade and self- } \\
\text { assessed grade } \\
\text { (Paired t-test) }\end{array}$ & & & & \\
\hline RQ1 & $\begin{array}{l}\text { Correlation between examiner grade and self-assessed } \\
\text { grade } \\
\text { (Pearson correlation test) }\end{array}$ & $\begin{array}{l}.27 \\
(\mathrm{p}<.001)\end{array}$ & $\begin{array}{l}.18 \\
(\mathrm{p}=.10)\end{array}$ & $\begin{array}{l}.18 \\
(\mathrm{p}=.10)\end{array}$ & $\begin{array}{l}-.08 \\
(\mathrm{p}=.28)\end{array}$ \\
\hline RQ2 & $\begin{array}{l}\text { Correlation between self-assessment accuracy and } \\
\text { iSAP performance } \\
\text { (Pearson correlation test) }\end{array}$ & $\begin{array}{l}.22 \\
(\mathrm{p}=.005)\end{array}$ & & & \\
\hline RQ3 & $\begin{array}{l}\text { Correlation between self-assessment accuracy and } \\
\text { exam question performance } \\
\text { (Pearson correlation test) }\end{array}$ & $\begin{array}{l}.13 \\
(\mathrm{p}=.11)\end{array}$ & & & \\
\hline RQ4 & $\begin{array}{l}\text { Correlation between self-assessment accuracy and } \\
\text { changes in students' performance } \\
\text { (Pearson correlation test) }\end{array}$ & $\begin{array}{l}-.04 \\
(\mathrm{p}=.58)\end{array}$ & & & \\
\hline \multirow[t]{3}{*}{ RQ4 } & $\begin{array}{l}\text { Changes in students' performance in the low awareness } \\
\text { group } \\
\text { (One way ANOVA) }\end{array}$ & & $\begin{array}{l}+1.13 \% \\
(\mathrm{p}=.84)\end{array}$ & $\begin{array}{l}-16.00 \% \\
(\mathrm{p}=.001)\end{array}$ & $\begin{array}{l}-24.73 \% \\
(\mathrm{p}<.001)\end{array}$ \\
\hline & $\begin{array}{l}\text { Changes in students' performance in the high } \\
\text { awareness group } \\
\text { (One way ANOVA) }\end{array}$ & & $\begin{array}{l}-3.65 \% \\
(p=.48)\end{array}$ & $\begin{array}{l}-25.13 \% \\
(p<.001)\end{array}$ & $\begin{array}{l}-23.16 \% \\
(p<.001)\end{array}$ \\
\hline & $\begin{array}{l}\text { Difference between changes in students' performance } \\
\text { of the high awareness and low awareness group } \\
\text { (Paired t-test) }\end{array}$ & & $\begin{array}{l}- \\
4.771 \% \\
(\mathrm{p}=.54)\end{array}$ & $\begin{array}{l}- \\
9.134 \% \\
(\mathrm{p}=.19)\end{array}$ & $\begin{array}{l}+1.567 \% \\
(\mathrm{p}=.79)\end{array}$ \\
\hline
\end{tabular}


Table 3. Themes Relating to iSAP Performance

\begin{tabular}{|c|c|c|}
\hline Major Themes & Sub-themes & Example \\
\hline $\begin{array}{l}\text { Analytic } \\
\text { processes }\end{array}$ & $\begin{array}{ll}\text { - } & \text { Needs to consider patient- } \\
& \text { specific factors } \\
\text { - } & \text { Should be more careful in } \\
\text { information gathering } \\
\text { - } \\
\text { - } \quad \text { Sacks ability to prioritise MRPs } \\
\text { management plan }\end{array}$ & $\begin{array}{l}\text { "I need to carefully read the admission notes, } \\
\text { to make sure I'm not missing any key points" }\end{array}$ \\
\hline Resources & $\begin{array}{l}\text { - } \\
\text { - } \\
\text { - } \text { resources to use more } \\
\text { - Should not trust one resource too } \\
\text { much } \\
\text { - Should familiarise with the } \\
\text { resources beforehand }\end{array}$ & $\begin{array}{l}\text { "Also, when the information is not cleared in } \\
\text { resources such as eTG or eviQ, I will consult } \\
\text { primary studies..." }\end{array}$ \\
\hline $\begin{array}{l}\text { Time } \\
\text { management }\end{array}$ & $\begin{array}{l}\text { Wasted time looking for trivial } \\
\text { MRPs } \\
\text { - Lacks ability to organise time } \\
\text { well } \\
\text { - Time constraint }\end{array}$ & $\begin{array}{l}\text { "I couldn't finish as I spent a great portion of } \\
\text { time going through the case..." }\end{array}$ \\
\hline $\begin{array}{l}\text { Perception of } \\
\text { the test }\end{array}$ & $\begin{array}{l}\text { Unaware that there could be } \\
\text { more than } 2 \text { MRPs } \\
\text { Misunderstood the purpose of } \\
\text { the test } \\
\text { - Confidence boost after hearing } \\
\text { expert's response }\end{array}$ & $\begin{array}{l}\text { "When assessing this case, I didn't realise } \\
\text { there were more than two possible MRPs" }\end{array}$ \\
\hline $\begin{array}{l}\text { Clinical } \\
\text { knowledge }\end{array}$ & $\begin{array}{l}\text { Lacks clinical knowledge of } \\
\text { condition and medical } \\
\text { medications }\end{array}$ & $\begin{array}{l}\text { "I think this is mainly because I was not very } \\
\text { familiar with the content for this topic" }\end{array}$ \\
\hline
\end{tabular}


Figure 1: Summary of the Sequence of Events for Students in Terms of Following the iSAP Format
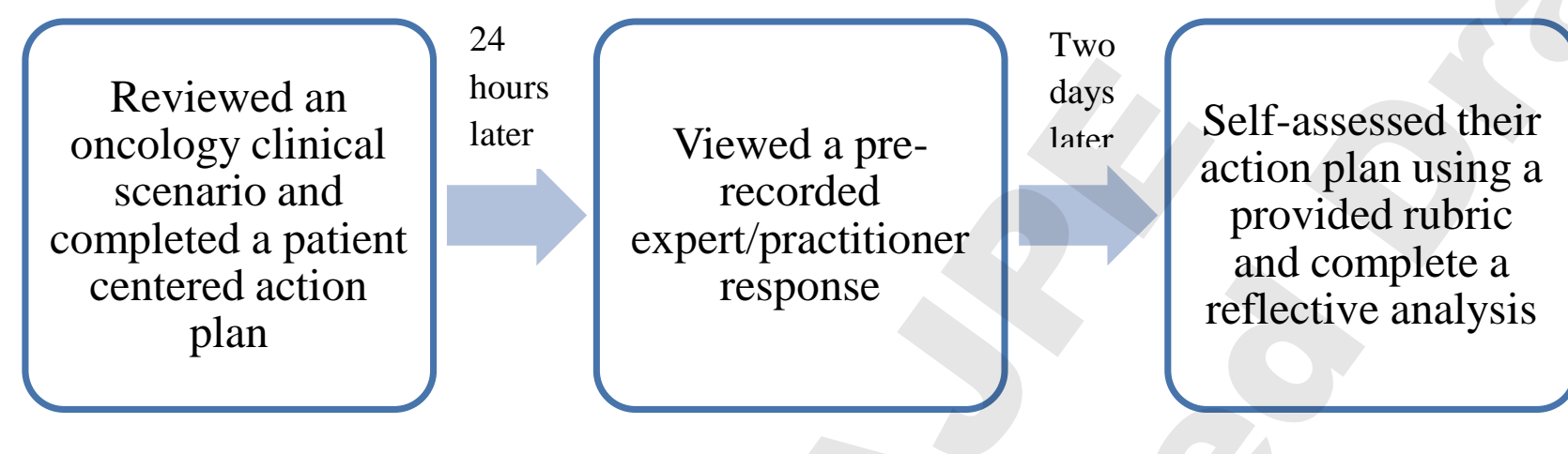

One

month

Completed an end of semester exam

that had a short answer question similar to the oncology clinical scenario 
Figure 2: Comparison of iSAP Assessment Marks from Examiners and Self-Assessment of Students Categorized Into Tertiles

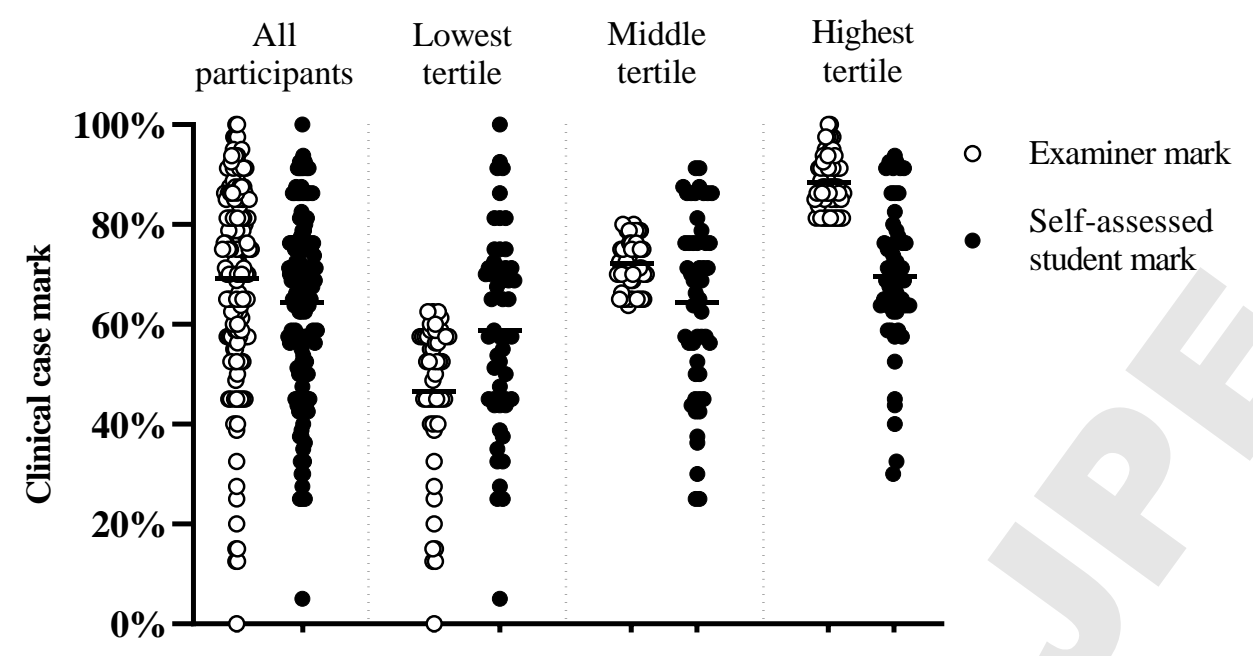

